\title{
Anti-neoplastic effects of fucoxanthin and its deacetylated product, fucoxanthinol, on Burkitt's and Hodgkin's lymphoma cells
}

\author{
SENJI TAFUKU $^{1}$, CHIE ISHIKAWA ${ }^{1,2}$, TAKESHI YASUMOTO $^{3}$ and NAOKI MORI ${ }^{1}$ \\ ${ }^{1}$ Department of Microbiology and Oncology, Graduate School of Medicine, University of the Ryukyus, \\ Nishihara, Okinawa 903-0215; ${ }^{2}$ Transdisciplinary Research Organization for Subtropics \\ and Island Studies, Nishihara, Okinawa 903-0213; ${ }^{3}$ Marine Bio Industry Division, \\ Okinawa Science and Technology Promotion Center, Naha, Okinawa 900-0029, Japan
}

Received May 10, 2012; Accepted July 6, 2012

DOI: $10.3892 / o r .2012 .1947$

\begin{abstract}
Fucoxanthin (FX) is a natural carotenoid with reported antitumorigenic activity. This study explored the effects of FX and its deacetylated product, fucoxanthinol (FXOH), on B-cell malignancies, including Burkitt's lymphoma, Hodgkin's lymphoma and Epstein-Barr virus-immortalized B cells. Both $\mathrm{FX}$ and $\mathrm{FXOH}$ reduced the viability of these malignant $\mathrm{B}$ cells in a dose-dependent manner accompanied by the induction of cell cycle arrest during $\mathrm{G}_{1}$ phase and caspase-dependent apoptosis. FXOH was approximately twice more potent than FX in these activities. In contrast, normal peripheral blood mononuclear cells were resistant to $\mathrm{FX}$ and $\mathrm{FXOH}$. Strong and constitutive activation of nuclear factor- $\kappa \mathrm{B}(\mathrm{NF}-\kappa \mathrm{B})$ is a common characteristic of many $\mathrm{B}$-cell malignancies, and $\mathrm{FXOH}$ suppressed constitutive NF- $\kappa \mathrm{B}$ activity. NF- $\kappa \mathrm{B}$ inhibition was accompanied by downregulation of NF- $\kappa \mathrm{B}$-dependent anti-apoptotic and cell cycle regulator gene products, including Bcl-2, cIAP-2, XIAP, cyclin D1 and cyclin D2. The results indicated that FX and FXOH are potentially useful therapeutic agents in B-cell malignancies characterized by aberrant regulation of $\mathrm{NF}-\kappa \mathrm{B}$.
\end{abstract}

\section{Introduction}

Epstein-Barr virus (EBV) is a ubiquitous human $\gamma$-herpesvirus and was the first human virus linked to cancer (1). EBV can infect and immortalize B-lymphocytes in vitro, giving rise to lymphoblastoid cell lines (LCLs). Consistent with this feature, persistent, latent EBV infection is present in several lymphoid malignancies including Burkitt's lymphoma (BL) and Hodgkin's lymphoma (HL) (2).

Correspondence to: Dr Naoki Mori, Department of Microbiology and Oncology, Graduate School of Medicine, University of the Ryukyus, 207 Uehara, Nishihara, Okinawa 903-0215, Japan E-mail: naokimori50@gmail.com

Key words: Burkitt's lymphoma, Hodgkin's lymphoma, fucoxanthin, fucoxanthinol, nuclear factor- $\kappa \mathrm{B}, \mathrm{B}$-cell malignancies
BL represents a subtype of high-grade mature B-cell non-Hodgkin's lymphoma and is characterized by rapid cell proliferation and a generally aggressive clinical course. BL is typically seen in areas where malaria is endemic and can represent up to $50 \%$ of childhood cancers in some regions. In this endemic form of BL disease, $\mathrm{EBV}$ is present in all cases. BL also occurs sporadically at lower incidence throughout the world with associated lower levels of EBV positivity (2). The frequency of BL has increased in low-incidence countries since the 1980s, following the advent of human immunodeficiency virus/acquired immunodeficiency syndrome, and among these cases 30-40\% of tumors are EBV-positive. Patients with human immunodeficiency virus-associated lymphoma pose additional therapeutic challenges, particularly the risk of overwhelming opportunistic infections (3).

HL is a B cell lymphoma generally comprising only a small proportion of the characteristic malignant Hodgkin/ Reed-Sternberg (HRS) cells, but with abundant non-malignant immunocytes recruited by various cytokines secreted by HRS cells. EBV is present in the HRS cells in $\sim 40 \%$ of classical HL cases (2). Although multidrug approaches have been very successful in the treatment of HL, unfortunately, latent toxicity of these agents appear after several years in the form of secondary malignancies and cardiovascular disease (4). In addition, some patients will suffer from refractory disease or experience a relapse. Therefore, the current goal in HL treatment is to find new therapies that specifically target the deregulated signaling cascades that cause HRS cell proliferation and resistance to apoptosis. In many cancers, nuclear factor- $\kappa \mathrm{B}(\mathrm{NF}-\kappa \mathrm{B})$ is constitutively activated, protecting the tumor cells against apoptosis. Indeed, lesions from patients with EBV-associated $\mathrm{B}$-cell lymphomas show activation of $\mathrm{NF}-\kappa \mathrm{B}$, and thus inhibition of NF- $\kappa \mathrm{B}$ is a much sought-after therapeutic target in a variety of cancers $(5,6)$.

Carotenoids are a family of natural pigments that include fucoxanthin (FX), an abundant constituent of edible brown algae. FX has several reported biological functions including anti-oxidant, anti-inflammatory, anti-cancer, anti-obesity, anti-diabetic, anti-angiogenic and anti-malarial activities (7). FX is also an inhibitor of pivotal proinflammatory mediators including nitric oxide and cytokines, and affects signaling molecules involved in the inflammatory processes such as 
$\mathrm{NF}-\kappa \mathrm{B}$ and mitogen-activated protein kinases (8). In mammals, dietary FX is deacetylated into fucoxanthinol (FXOH) in the intestinal tract by lipases and esterases from the pancreas or intestinal cells, and is then incorporated as $\mathrm{FXOH}$ into the blood circulation (7).

This study tested the hypothesis that FX and $\mathrm{FXOH}$, through the inhibition of $\mathrm{NF}-\kappa \mathrm{B}$, could be potentially useful therapeutic agents in the treatment of BL and HL.

\section{Materials and methods}

Extraction and isolation. FX was extracted from the brown seaweed Cladosiphon okamuranus Tokida using acetone as the solvent, and purified by column chromatography, liquidliquid partition, and then recrystallization up to $>95 \%$ purity. It was further purified by RP-HPLC up to $>98 \%$ purity, in preparation for in vitro assays. $\mathrm{FXOH}$ was prepared by enzymatic hydrolysis of the purified FX using porcine pancreatic lipase. Briefly, $195 \mathrm{mg}$ of FX, $2 \mathrm{~g}$ of sodium taurocholate and $2 \mathrm{~g}$ of porcine pancreatic lipase (Type II; Sigma-Aldrich, St. Louis, MO) were dissolved in $30 \mathrm{ml}$ of $0.1 \mathrm{M}$ sodium phosphate buffer (pH 7.0). The reaction buffer was incubated at $37^{\circ} \mathrm{C}$ for $3 \mathrm{~h}$. FXOH was purified by ODS column chromatography, liquidliquid partition and recrystallization. We prepared $142 \mathrm{mg}$ of purified FXOH for this study ( $>95 \%$ purity, $72 \%$ yield). The FXOH was also further purified up to $>98 \%$ purity by RP-HPLC, for in vitro assays. The identity and purity of the products were confirmed by comparison with reference FX (Wako Pure Chemical Industries, Osaka, Japan) and data in the literature.

Cells and cultures. Raji and Daudi are EBV-positive BL cell lines, whereas BJAB and Ramos are EBV-negative BL cell lines. B95-8/Ramos and B95-8/BJAB are Ramos and BJAB cells, respectively, infected with the B95-8 strain of EBV. LCL-Ka and LCL-Ku are EBV-immortalized human B-cell lines generated from peripheral blood mononuclear cells (PBMC) of healthy volunteers. PBMC were isolated by Ficoll-Paque density gradient centrifugation (GE Healthcare Biosciences, Uppsala, Sweden) and washed with phosphate-buffered saline. L428, KM-H2, HDLM-2 and L540 are HL cell lines. All cell lines were cultured in Roswell Park Memorial Institute-1640 medium supplemented with 10 or $20 \%$ heat-inactivated fetal bovine serum, $50 \mathrm{U} / \mathrm{ml}$ penicillin and $50 \mu \mathrm{g} / \mathrm{ml}$ streptomycin.

Cell viability and assay of apoptosis. The effects of FX and FXOH on cell viability were assessed using water-soluble tetrazolium (WST)-8 (Wako Pure Chemical Industries). Briefly, $1 \times 10^{5}$ cells $/ \mathrm{ml}$ were incubated in a $96-$ well microculture plate in the absence or presence of various concentrations of FX or FXOH. After 24-h culture, WST-8 (5 $\mu \mathrm{l})$ was added for the last $4 \mathrm{~h}$ of incubation and the absorbance at $450 \mathrm{~nm}$ was measured using an automated microplate reader. Mitochondrial dehydrogenase cleavage of WST-8 to formazan dye provided a measure of cell proliferation. Apoptotic events in cells were detected by staining with phycoerythrin-conjugated Apo2.7 monoclonal antibody (Beckman-Coulter, Marseille, France) (9) and analyzed by flow cytometry (Epics XL, Beckman-Coulter, Fullerton, CA).
Cell cycle analysis. Cell cycle analysis was performed with the Cycletest $^{\mathrm{TM}}$ Plus DNA DNA reagent kit (Becton-Dickinson Immunocytometry Systems, San Jose, CA). Briefly, 1x10 cells were washed with a buffer solution containing sodium citrate, sucrose and dimethyl sulfoxide, suspended in a solution containing RNase A, and then stained with $125 \mu \mathrm{g} / \mathrm{ml}$ propidium iodide for $10 \mathrm{~min}$. Cell suspensions were analyzed on a Coulter EPICS XL using EXPO32 software. The population of cells in each cell cycle phase was determined with MultiCycle software.

In vitro measurement of caspase activity. Caspase activity was measured with the colorimetric caspase assay kits (MBL, Nagoya, Japan). Cell extracts were prepared using cell lysis buffer and assessed for caspases- 3 and -9 activities using colorimetric probes. Colorimetric caspase assay kits are based on detection of the chromophore $p$-nitroanilide after cleavage from caspasespecific-labeled substrates. Colorimetric readings were performed in an automated microplate reader at an optical density of $405 \mathrm{~nm}$.

Western blotting. Cells were lysed in a buffer containing $62.5 \mathrm{mM}$ Tris- $\mathrm{HCl}$ (pH 6.8), $2 \%$ sodium dodecyl sulphate (SDS), $10 \%$ glycerol, $6 \%$ 2-mercaptoethanol and $0.01 \%$ bromophenol blue. Equal amounts of protein $(20 \mu \mathrm{g})$ were subjected to electrophoresis on SDS-polyacrylamide gels followed by transfer to a polyvinylidene difluoride membrane and probing with the specific antibodies. The bands were visualized by enhanced chemiluminescence (GE Healthcare, Buckinghamshire, UK).

Antibodies to cyclin D2, cIAP-2, I $\mathrm{B} \alpha$ and NF- $\kappa \mathrm{B}$ subunits p50, p65, c-Rel, p52 and RelB were purchased from Santa Cruz Biotechnology (Santa Cruz, CA). Antibodies to Bax, Bcl-2 and actin were purchased from NeoMarkers (Fremont, CA). Antibodies to XIAP and cyclin D1 were obtained from Medical \& Biological Laboratories (MBL, Nagoya, Japan). Antibodies to survivin, caspase-3, $-9, \mathrm{Bcl}-\mathrm{x}_{\mathrm{L}}$ and phospho-IкB $\alpha$ (Ser32 and Ser36) were purchased from Cell Signaling Technology (Beverly, MA). The antibody to poly(ADP-ribose) polymerase (PARP) was purchased from BD Transduction Laboratories (San Jose, CA).

Preparation of nuclear extracts and electrophoretic mobility shift assay (EMSA). Cells were cultured and examined for inhibition of NF- $\mathrm{BB}$ after exposure to $\mathrm{FXOH}$ for $24 \mathrm{~h}$. Nuclear proteins were extracted as described by Antalis and Godbolt (10) with modifications, and NF- $\kappa$ B binding activity to the NF- $\kappa \mathrm{B}$ element was examined by EMSA. Briefly, $5 \mu \mathrm{g}$ of nuclear extracts were preincubated in a binding buffer containing $1 \mu \mathrm{g}$ poly-deoxy-inosinic-deoxycytidylic acid (GE Healthcare Biosciences), followed by the addition of ${ }^{32} \mathrm{P}$-labeled oligonucleotide probes containing the NF- $\kappa \mathrm{B}$ element. The mixtures were incubated for $15 \mathrm{~min}$ at room temperature. The DNA protein complexes were separated on $4 \%$ polyacrylamide gels and visualized by autoradiography. The probes and competitors used were prepared by annealing the sense and antisense synthetic oligonucleotides as follows: a typical $\mathrm{NF}-\kappa \mathrm{B}$ element from the IL-2 receptor $\alpha$ chain (IL-2R $\alpha$ ) gene (5'-gatcCGGCAGGGGAATCTCCCTCTC-3') and an AP-1 element of the IL-8 gene (5'-gatcGTGATGACTCAGGTT-3'). The above underlined sequences represent the $N F-\kappa B$ and AP-1 binding sites, respectively. 

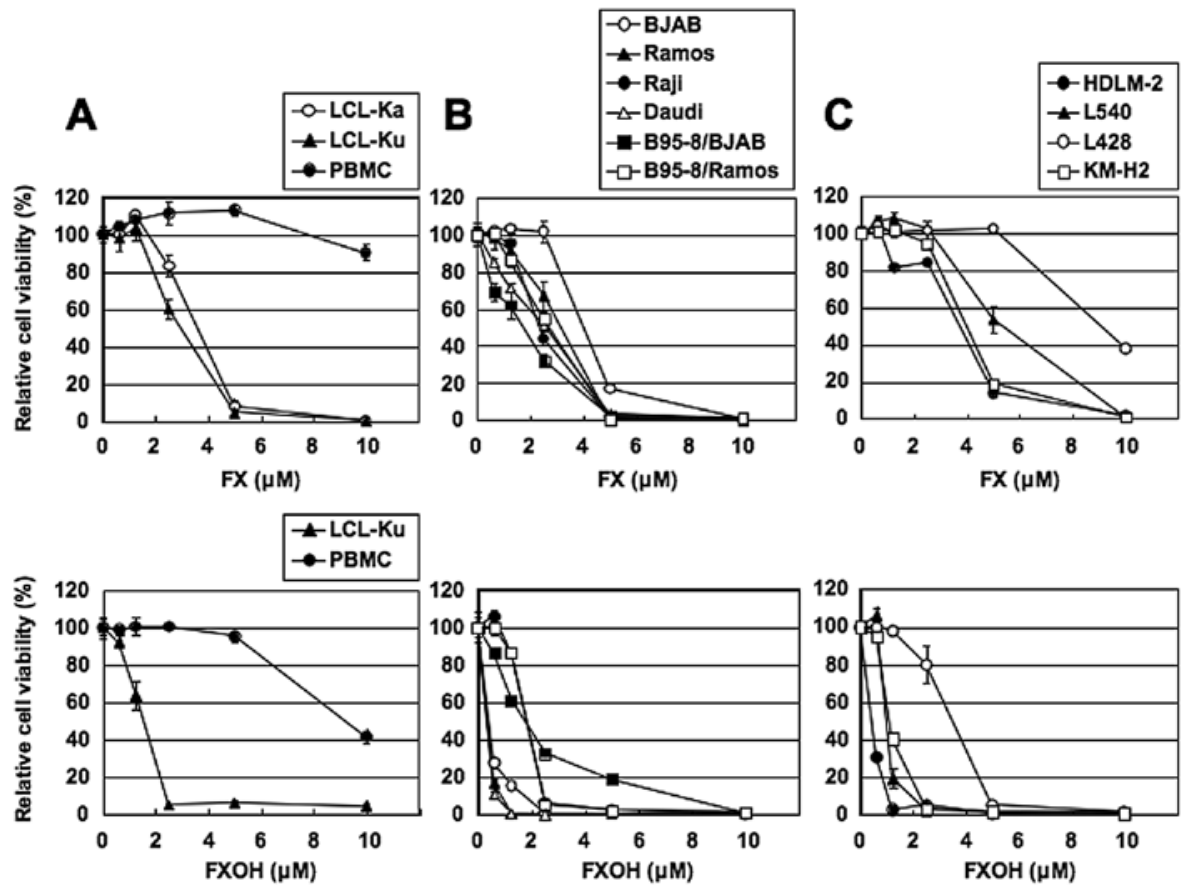

Figure 1. FX and FXOH reduce cell viability of EBV-immortalized human B (A), BL (B) and HL cell lines (C). Cell lines and PBMC from a healthy control were incubated in the presence of various concentrations of FX or FXOH for $24 \mathrm{~h}$. The viability of the cultured cells was determined by WST- 8 assay. Relative viability of the cultured cells is presented as the mean \pm SD determined for cells from triplicate cultures.
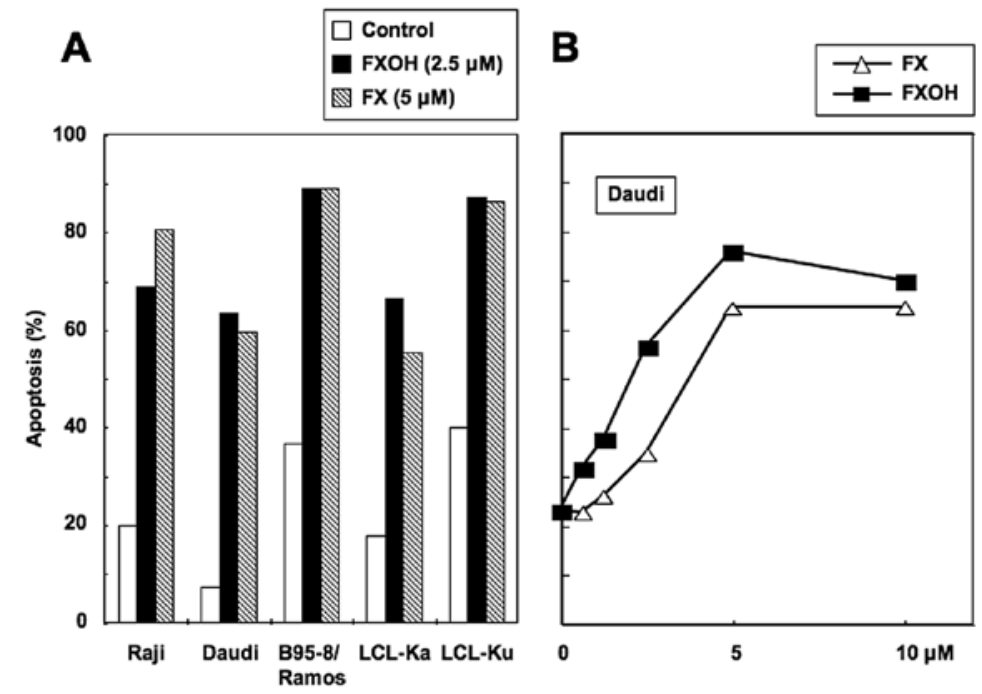

Figure 2. FX and FXOH induce apoptosis. (A) Cell lines were incubated with or without FX $(5 \mu \mathrm{M})$ or FXOH $(2.5 \mu \mathrm{M})$ for $24 \mathrm{~h}$. (B) Daudi cells were treated with various concentrations of FX or FXOH for $24 \mathrm{~h}$. Cells were harvested, then stained with the Apo2.7 monoclonal antibody and analyzed by flow cytometry. Data are percentages of apoptotic cells.

\section{Results}

FX and FXOH reduce cell viability of EBV-immortalized human $B$-cell lines, BL and HL cell lines. We first examined the effects of $\mathrm{FX}$ and $\mathrm{FXOH}$ on the cell viability of EBV-immortalized human B-cell lines. Cells cultured in the presence of various concentrations of $\mathrm{FX}$ or $\mathrm{FXOH}$ for $24 \mathrm{~h}$ showed dose-dependent decrease in cell viability in two EBV-immortalized human B-cell lines, as assessed by WST-8 assay (Fig. 1A). PBMC from healthy volunteers were less susceptible to $\mathrm{FX}$ and $\mathrm{FXOH}$ than the human B-cell lines. Treatment of EBV-positive and -negative BL cell lines (Fig. 1B) and HL cell lines (Fig. 1C) with FX or
FXOH also resulted in lower cell viability. The FXOH-induced suppression of cell viability was more pronounced than that induced by FX.

FX and FXOH induce apoptosis. We next examined whether induction of apoptosis accounted for the reduced cell viability observed in these cell lines. Cells were treated with $5 \mu \mathrm{M}$ of FX or $2.5 \mu \mathrm{M}$ of FXOH and then probed with the Apo2.7 monoclonal antibody. FX $(5 \mu \mathrm{M})$ and $\mathrm{FXOH}(2.5 \mu \mathrm{M})$ increased the proportion of apoptotic cells in EBV-immortalized human B-cell lines and BL cell lines by similar levels (Fig. 2A). Exposure of Daudi cells to FX and FXOH also induced apoptosis in a dose-depen- 


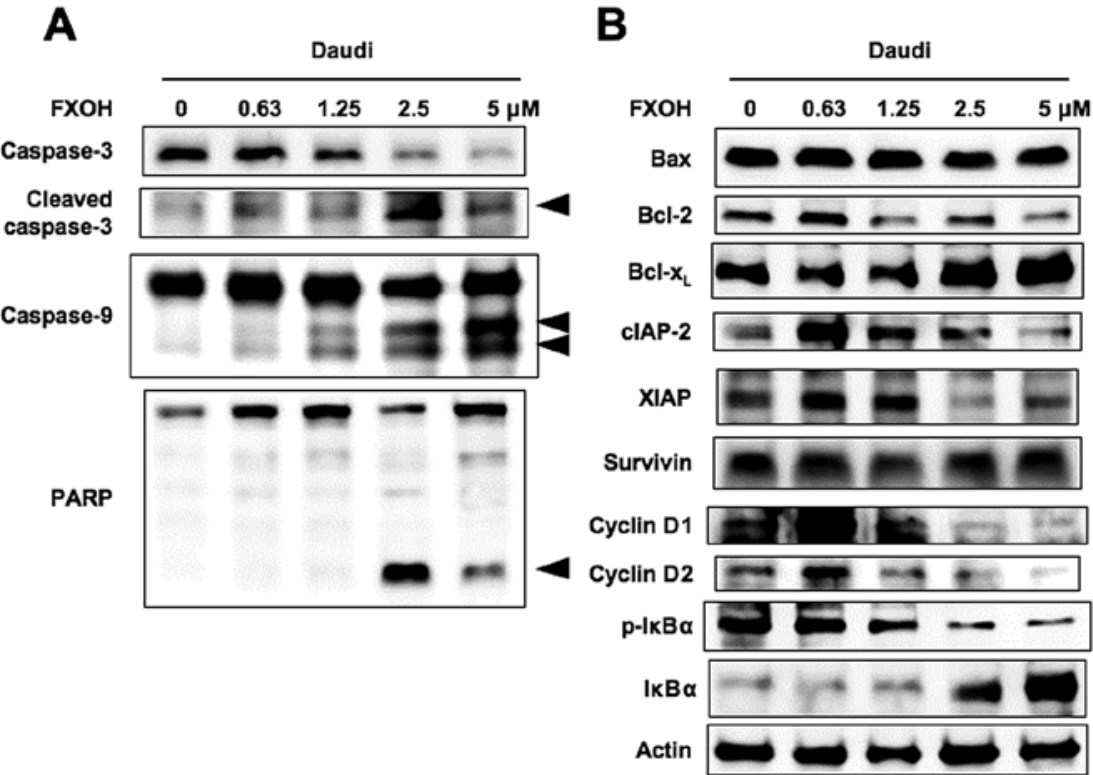

Figure 3. Western blot analysis. (A) Induction of caspase activity by FXOH. Daudi cells were incubated with the indicated concentrations of FXOH for 24 h. Cellular proteins were resolved by SDS/polyacrylamide gel electrophoresis, and caspase activity was detected by cleavage of PARP, caspase-3 and -9 using immunoblot analysis. Arrowheads indicate the cleaved forms of PARP, caspase-3 and -9. (B) FXOH inhibits the expression of NF- $\mathrm{B}$-regulated proteins involved in driving cell proliferation and survival, as well as upstream events in the NF- $\mathrm{BB}$ pathway. Daudi cells were incubated with the indicated concentrations of FXOH for $24 \mathrm{~h}$. The content of different apoptosis and cell cycle regulatory proteins as well as phosphorylated and total IкB $\alpha$ was evaluated by western blotting. Actin was used as a protein-loading control.

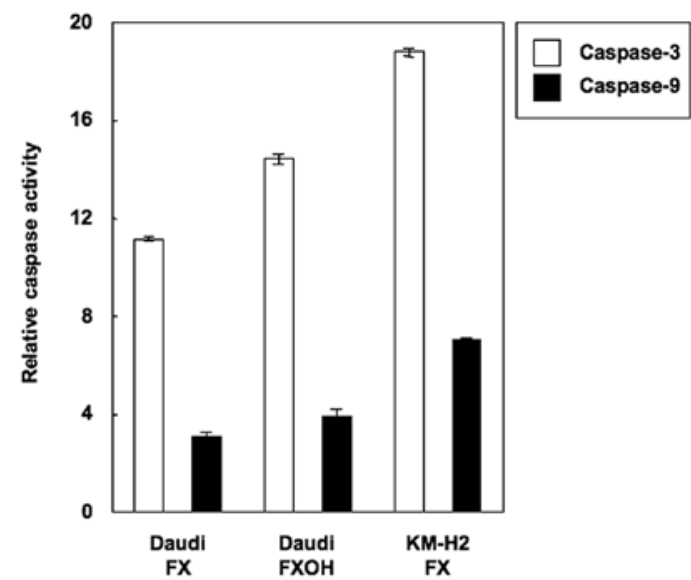

Figure 4. FX and FXOH induce caspase activities. Daudi and KM-H2 cells were treated with or without FX $(10 \mu \mathrm{M})$ or FXOH $(5 \mu \mathrm{M})$. After $6 \mathrm{~h}$, cell lysates were prepared and incubated with the labeled caspase substrates, and caspase activity was measured using an automated microplate reader. Caspase activity is expressed relative to untreated cells, which were assigned a value of 1 . Values are mean $\pm \operatorname{SD}(n=3)$.

dent manner (Fig. 2B). The FXOH-induced apoptosis was more pronounced than that induced by FX. These results indicate that the inhibitory effects of FX and FXOH on the viability of cell lines reflect the agents' pro-apoptotic properties.

FX- and FXOH-induced apoptosis is caspase-dependent. We next investigated whether the observed apoptosis was due to caspase activation. Cell extracts were obtained after various treatments and processed for immunoblot analysis. As shown in Fig. 3A, immunoblot analysis demonstrated the cleaved products of PARP, caspases -3 and -9 induced by $\mathrm{FXOH}$ in a dose-dependent manner. The immunoblotting allowed us to examine the processing of caspases, but did not indicate whether the cleavage products were enzymatically active. Therefore, caspases- 3 and -9 activities were determined by cleavage of caspase-specific-labeled substrates in colorimetric assays. Both FX and FXOH activated caspase-3 and -9 in Daudi and KM-H2 cells (Fig. 4). These results indicated that caspase activation plays a role in the FX- and $\mathrm{FXOH}$-induced apoptosis observed in these cell lines.

$F X$ and $F X O H$ cause $G_{I}$ cell cycle arrest. We next examined the effects of FX and $\mathrm{FXOH}$ on cell cycle-regulatory mechanisms using Daudi, KM-H2 and L540 cells. Cultivation with $2.5 \mu \mathrm{M}$ of $\mathrm{FX}$ or $1.25 \mu \mathrm{M}$ of $\mathrm{FXOH}$ for $24 \mathrm{~h}$ increased the population of cells in the $\mathrm{G}_{1}$ phase, with reduced numbers of cells in the $\mathrm{S}$ phase, relative to untreated cells (Fig. 5). Thus, FX and FXOH suppressed the proliferation of BL and HL cell lines by arresting the cells in the $G_{1}$ phase of the cell cycle.

Effects of $\mathrm{FXOH}$ on the expression of apoptosis and cell cycle regulatory proteins. To clarify the molecular mechanisms of FX- and FXOH-induced inhibition of cell growth and apoptosis, we used western blot analysis to investigate the mechanism of FXOH-induced changes in the expression of several intracellular regulators of cell cycle and apoptosis. As shown in Fig. 3B, FXOH did not alter the expression levels of anti-apoptotic proteins Bcl- $\mathrm{x}_{\mathrm{L}}$ and survivin, or pro-apoptotic protein Bax. In contrast, FXOH downregulated the expression levels of anti-apoptotic proteins Bcl-2, cIAP-2 and XIAP in a dose-dependent manner. Furthermore, FXOH downregulated the expression levels of cell cycle regulatory proteins cyclins D1 and D2 dose-dependently. The results demonstrated that FXOH-mediated growth inhibition and apoptosis was associated with reduced expression of Bcl-2, cIAP-2, XIAP, cyclin D1 and cyclin D2 in the Daudi cells. 


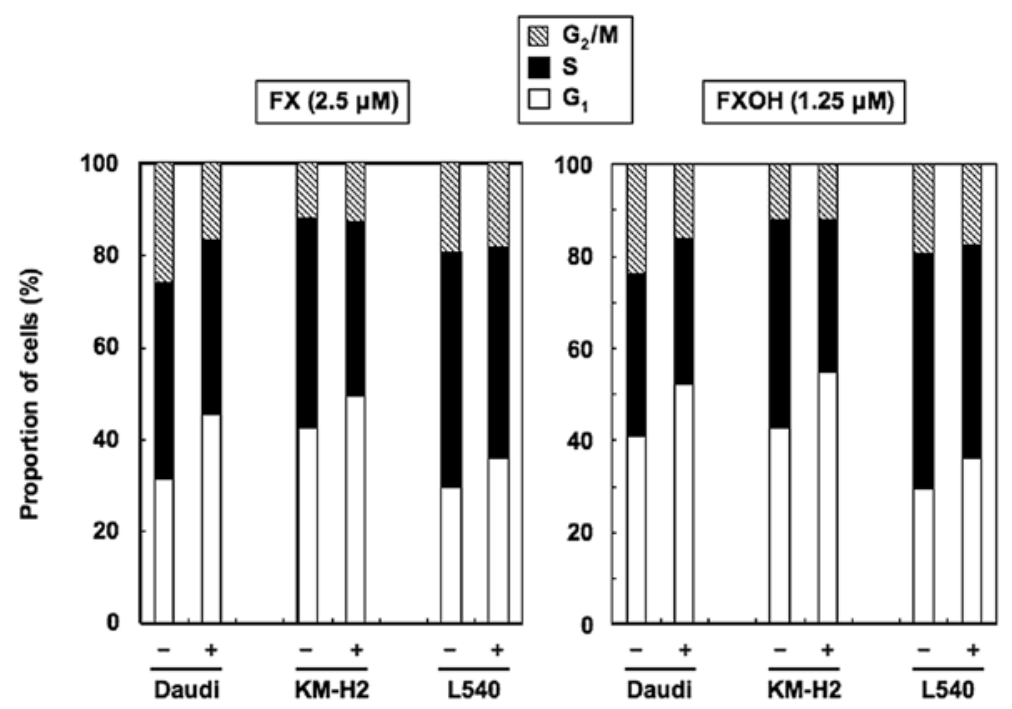

Figure 5. FX and FXOH induce $\mathrm{G}_{1}$ cell cycle arrest in BL and HL cell lines. Daudi, KM-H2 and L540 cells were incubated in the absence or presence of FX (2.5 $\left.\mu \mathrm{M}\right)$ or FXOH $(1.25 \mu \mathrm{M})$ for $24 \mathrm{~h}$. Then, the cells were washed, fixed, stained with propidium iodide, and analyzed for DNA content by flow cytometry.
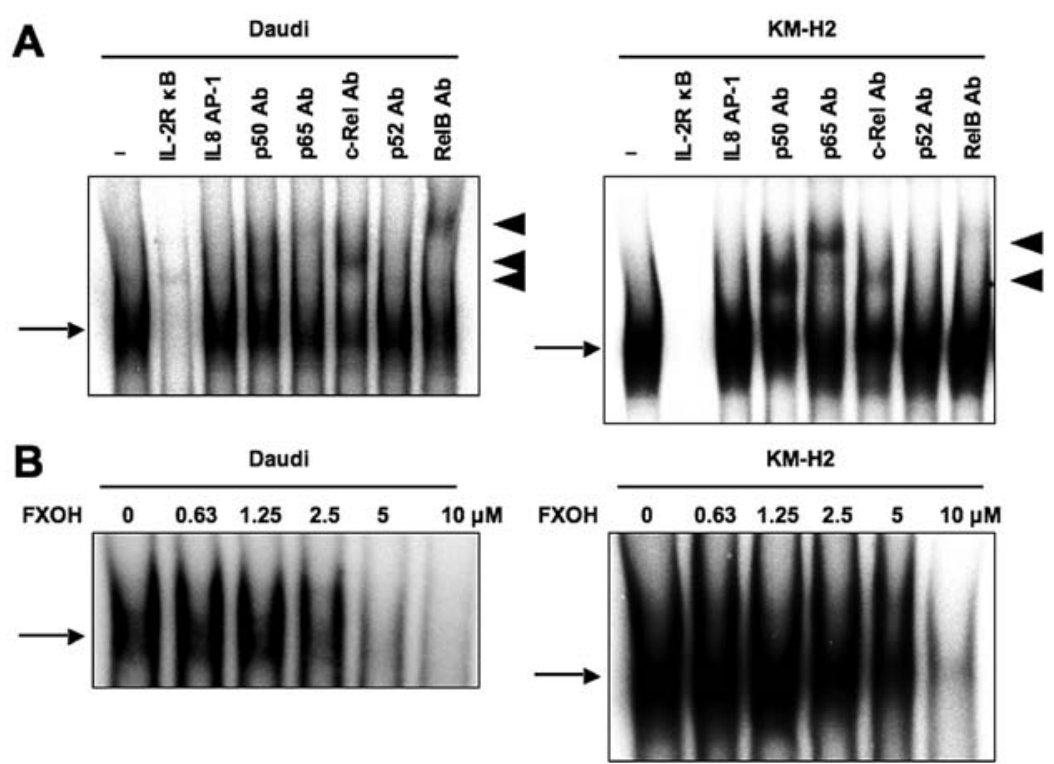

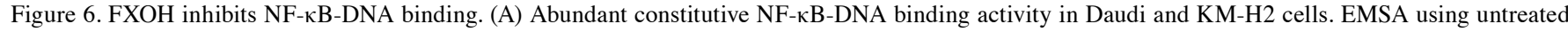
Daudi and KM-H2 nuclear extracts and radiolabeled NF- $\mathrm{KB}$ probe generated DNA-protein complexes, which were eliminated by 100 -fold molar excess of self-competitors, but not by the same molar excess of the irrespective oligonucleotides. Supershift assays using the radiolabeled NF- $\mathrm{kB}$ probe, untreated nuclear extracts and the indicated antibodies (Ab) to NF- $\mathrm{kB}$ components showed that the NF- $\mathrm{\kappa B}$ bands consisted of p50, p65, c-Rel and RelB subunits. Arrows, the specific complexes; arrowheads, the DNA binding complexes supershifted by antibodies. (B) Effect of FXOH on NF-kB-DNA binding activity. Daudi and KM-H2 cells were treated with the indicated concentrations of FXOH for $24 \mathrm{~h}$. Nuclear extracts were examined for NF- $\mathrm{kB}-\mathrm{DNA}$ binding activity by EMSA.

Inhibitory effects of $F X O H$ on $N F-\kappa B$ activity. Mammalian NF- $\kappa B$ characterizes a family of five transcription factors: RelA/

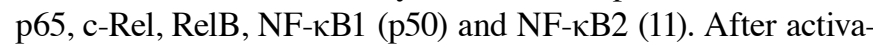
tion, the NF- $\kappa \mathrm{B}$ heterodimer is rapidly translocated to the nucleus, where it activates the transcription of target genes (12). Because Bcl-2, cIAP-2, XIAP, cyclin D1 and cyclin D2 are NF- $\kappa$ B target genes (12-18), we examined whether FXOH directly inhibits the

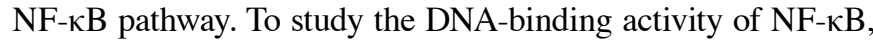
we performed EMSA with radiolabeled double-stranded NF- $\mathrm{kB}$ oligonucleotides and nuclear extracts from Daudi and KM-H2 cells, and confirmed the constitutive activation of NF- $\kappa \mathrm{B}$ in these cells. Supershift analysis showed that the NF- $\mathrm{KB}$ bands were composed of p50, p65, c-Rel and RelB subunits (Fig. 6A). We next examined the effects of FXOH on Daudi and KM-H2 cells in this context by EMSA and found reduced DNA binding to NF- $\mathrm{KB}$ in a dose-dependent manner (Fig. 6B), suggesting that $\mathrm{FXOH}$ could inhibit the DNA-binding activity of NF- $\mathrm{KB}$.

$\mathrm{NF}-\kappa \mathrm{B}$ is inactive in the cytosol where it is bound to I $\kappa \mathrm{B}$, and only becomes active after I $\mathrm{K}$ has been phosphorylated and subsequently degraded (11). Immunoblotting showed that in the absence of $\mathrm{FXOH}$, the levels of phosphorylated I $\mathrm{B} \alpha \alpha$ steadily increased in Daudi cells (Fig. 3B). FXOH thus reduced the phosphorylation and degradation of $\mathrm{I} \kappa \mathrm{B} \alpha$ in a dose-dependent manner. These results indicated that FXOH inhibits NF- $\mathrm{kB}$ 
activation by preventing the degradation of phosphorylated IкB $\alpha$.

\section{Discussion}

The main issue addressed in this study was whether FX and FXOH have inhibitory activity against human B-cell malignancies including BL and $\mathrm{HL}$, and the possible mechanisms underlying such activities. Because of its central role in cell proliferation and survival, the $\mathrm{NF}-\kappa \mathrm{B}$ transcription factor has become an important molecular marker of the malignant transformation of cells, especially in hematopoietic malignancies $(5,19)$, and particularly in the pathogenesis of BL and HL (19-21). The present study therefore characterized this transcription factor as a good target for the treatment of BL and $\operatorname{HL}(19,20)$. FX is one of the most biologically active and abundantly found carotenoids (7). Our findings strongly suggested that FX and its deacetylated product, $\mathrm{FXOH}$, inhibit constitutive NF- $\kappa \mathrm{B}$ activation via the I $\kappa \mathrm{B} \alpha$ phosphorylation mechanism, resulting in less cell proliferation and increased cell death by apoptosis. Such results encourage the search for novel carotenoids for the treatment of cancers characterized by aberrant regulation of NF- $\mathrm{NB}$.

FX was hydrolyzed to FXOH during uptake by Caco-2 cells, a tissue culture model for studying the absorption of dietary compounds by human intestinal epithelium (22). Dietary FX is also thought to be hydrolyzed to $\mathrm{FXOH}$ in the mammalian gastrointestinal tract by digestive enzymes such as lipase and cholesterol esterase before being absorbed into intestinal cells (22). It was also reported that $\mathrm{FXOH}$ is a major metabolite of dietary FX in humans, implying that the major compound in the circulation after FX intake is FXOH (23). Therefore, the bioavailability of $\mathrm{FXOH}$ is higher than that of $\mathrm{FX}$ in the body. In addition, our study found that $\mathrm{FXOH}$ was more potent in inducing apoptosis than FX in the BL and HL cell lines. Taken together, it seems likely that most dietary FX is converted to FXOH, which could then exert a suppressive effect on cells at concentrations lower than the effective concentrations of FX used in the present study.

A dose-dependent suppression of $\mathrm{NF}-\kappa \mathrm{B}$ constitutive activity by $\mathrm{FXOH}$ was also observed in the BL and HL cell lines studied here. In Daudi and KM-H2 cells, FXOH inhibited $\mathrm{NF}-\kappa \mathrm{B}-\mathrm{DNA}$ binding by preventing $\mathrm{I} \kappa \mathrm{B} \alpha$ phosphorylation, which is a crucial prerequisite to $N F-\kappa B-D N A$ binding. The capacity of $\mathrm{FXOH}$ to inhibit nuclear NF- $\mathrm{NB}-\mathrm{DNA}$ binding was associated with the inhibition of $\mathrm{NF}-\kappa \mathrm{B}$-regulated gene expression. In this regard, $\mathrm{FXOH}$ reduced the expression of genes involved in cell proliferation (cyclins D1 and D2) and anti-apoptosis (Bcl-2, cIAP-2 and XIAP). The decrease in cell viability could be associated with a decreased cell proliferation and/or an increase in apoptotic cell death, and both D-type cyclins play a key role in cell proliferation through the activation of cyclin-dependent kinases (24). Furthermore, both cyclins are required for the progression of cells from the $G_{1}$ phase to the $S$ phase of the cell cycle (24). This scenario could therefore explain our findings that $\mathrm{FXOH}$ induces $\mathrm{G}_{1} / \mathrm{S}$ cell cycle arrest and thus inhibits cell proliferation.

We found that both FX and $\mathrm{FXOH}$ induced apoptosis of cells, accompanied by activation of caspases-3 and -9. A possible mechanism underlying the induction of apoptosis by $\mathrm{FXOH}$ could be its capacity to inhibit NF- $\mathrm{NB}$-regulated anti-apoptotic proteins. Bcl-2 prevents the process of mitochondrial release of pro-apoptotic factors, such as cytochrome c (25), and treatment of Daudi cells with FXOH in this study caused a reduction in Bcl-2 expression as well as other NF- $\mathrm{B}$-dependent anti-apoptotic proteins, cIAP-2 and XIAP $(14,15)$. These IAP proteins are known to inhibit both extrinsic (i.e., death receptor) and intrinsic (i.e., mitochondrial) pathways of apoptosis; cIAP-2 and XIAP directly bind and inhibit effector caspases, acting downstream of the initiator caspases. Our results demonstrated that FXOH induces apoptosis through downregulation of $\mathrm{NF}-\kappa \mathrm{B}-\mathrm{dependent}$ gene products, Bcl-2, cIAP-2 and XIAP.

Notably, FX and FXOH up to 10 and $5 \mu \mathrm{M}$, respectively, did not inhibit cell viability of PBMC from healthy volunteers that presented no $\mathrm{NF}-\kappa \mathrm{B}$ activity. These results together indicated that inhibition of NF- $\mathrm{NB}$ activity and of NF- $\mathrm{NB}$ dependent expression of cell survival proteins plays a major role in the pro-apoptotic activity of $\mathrm{FX}$ and $\mathrm{FXOH}$ in $\mathrm{B}$ cell malignancies.

In conclusion, this study demonstrated that $\mathrm{FX}$ and $\mathrm{FXOH}$ can inhibit $\mathrm{NF}-\kappa \mathrm{B}$ constitutive activation in BL and HL cell lines. The ability of both carotenoids to reduce cell viability reflects their capacity to decrease cell proliferation by causing $\mathrm{G}_{1}$ cell cycle arrest and to induce apoptotic cell death. The observed effects combined with the well-established pharmacological safety of both carotenoids (7) provide strong rationale for the potential use of $\mathrm{FX}$ and $\mathrm{FXOH}$ as new therapeutic agents for patients with BL and HL.

\section{Acknowledgements}

We acknowledge Dr Takeshi Sairenji for providing B95-8/ Ramos and B95-8/BJAB.

\section{References}

1. Epstein MA, Achong BG and Barr YM: Virus particles in cultured lymphoblasts from Burkitt's lymphoma. Lancet 1: 702-703, 1964.

2. Taylor GS and Blackbourn DJ: Infectious agents in human cancers: lessons in immunity and immunomodulation from gammaherpesviruses EBV and KSHV. Cancer Lett 305: 263-278, 2011.

3. Mounier N, Spina M and Gisselbrecht C: Modern management of non-Hodgkin lymphoma in HIV-infected patients. Br J Haematol 136: 685-698, 2007.

4. Re D, Thomas RK, Behringer K and Diehl V: From Hodgkin disease to Hodgkin lymphoma: biologic insights and therapeutic potential. Blood 105: 4553-4560, 2005.

5. Chaturvedi MM, Sung B, Yadav VR, Kannappan R and Aggarwal BB: $\mathrm{NF}-\kappa \mathrm{B}$ addiction and its role in cancer: 'one size does not fit all'. Oncogene 30: 1615-1630, 2011.

6. Liebowitz D: Epstein-Barr virus and a cellular signaling pathway in lymphomas from immunosuppressed patients. N Engl J Med 338: 1413-1421, 1998.

7. Peng J, Yuan J-P, Wu C-F and Wang J-H: Fucoxanthin, a marine carotenoid present in brown seaweeds and diatoms: metabolism and bioactivities relevant to human health. Mar Drugs 9: 1806-1828, 2011

8. Kim K-N, Heo S-J, Yoon W-J, Kang S-M, Ahn G, Yi T-H and Jeon Y-J: Fucoxanthin inhibits the inflammatory response by suppressing the activation of $\mathrm{NF}-\kappa \mathrm{B}$ and MAPKs in lipopolysaccharide-induced RAW 264.7 macrophages. Eur J Pharmacol 649: 369-375, 2010

9. Zhang C, Ao Z, Seth A and Schlossman SF: A mitochondrial membrane protein defined by a novel monoclonal antibody is preferentially detected in apoptotic cells. J Immunol 157: 3980-3987, 1996.

10. Antalis TM and Godbolt D: Isolation of intact nuclei from hematopoietic cell types. Nucleic Acids Res 19: 4301, 1991. 
11. Vallabhapurapu S and Karin M: Regulation and function of NF- $\kappa \mathrm{B}$ transcription factors in the immune system. Annu Rev Immunol 27: 693-733, 2009.

12. Pahl HL: Activators and target genes of Rel/NF- $\mathrm{kB}$ transcription factors. Oncogene 18: 6853-6866, 1999.

13. Grossmann M, O'Reilly LA, Gugasyan R, Strasser A, Adams JM and Gerondakis S: The anti-apoptotic activities of Rel and RelA required during $\mathrm{B}$-cell maturation involve the regulation of $\mathrm{Bcl}-2$ expression. EMBO J 19: 6351-6360, 2000.

14. Wäldele K, Silbermann K, Schneider G, Ruckes T, Cullen BR and Grassmann R: Requirement of the human T-cell leukemia virus (HTLV-1) tax-stimulated HIAP-1 gene for the survival of transformed lymphocytes. Blood 107: 4491-4499, 2006.

15. Stehlik C, de Martin R, Kumabashiri I, Schmid JA, Binder BR and Lipp J: Nuclear factor (NF)- $\kappa B$-regulated X-chromosomelinked iap gene expression protects endothelial cells from tumor necrosis factor $\alpha$-induced apoptosis. J Exp Med 188: 211-216, 1998.

16. Iwanaga R, Ohtani K, Hayashi T and Nakamura M: Molecular mechanism of cell cycle progression induced by the oncogene product Tax of human T-cell leukemia virus type I. Oncogene 20: 2055-2067, 2001.

17. Huang Y, Ohtani K, Iwanaga R, Matsumura Y and Nakamura M: Direct trans-activation of the human cyclin D2 gene by the oncogene product Tax of human T-cell leukemia virus type I. Oncogene 20: 1094-1102, 2001.
18. Hinz M, Krappmann D, Eichten A, Heder A, Scheidereit C and Strauss M: NF- $\kappa B$ function in growth control: regulation of cyclin D1 expression and $\mathrm{G}_{0} / \mathrm{G}_{1}$-to-S-phase transition. Mol Cell Biol 19: 2690-2698, 1999.

19. Jost PJ and Ruland J: Aberrant NF- $\mathrm{BB}$ signaling in lymphoma: mechanisms, consequences, and therapeutic implications. Blood 109: 2700-2707, 2007.

20. Kimura N, Miyakawa Y, Kohmura K, Umezawa K, Ikeda Y and Kizaki M: Targeting NF- $\mathrm{KB}$ and induction of apoptosis by novel NF- $\kappa$ B inhibitor dehydroxymethylepoxyquinomicin (DHMEQ) in Burkitt lymphoma cells. Leuk Res 31: 1529-1535, 2007.

21. Küppers R: Molecular biology of Hodgkin lymphoma. Hematology Am Soc Hematol Educ Program, pp491-496, 2009.

22. Sugawara T, Baskaran V, Tsuzuki W and Nagao A: Brown algae fucoxanthin is hydrolyzed to fucoxanthinol during absorption by Caco-2 human intestinal cells and mice. J Nutr 132: 946-951, 2002.

23. Asai A, Yonekura L and Nagao A: Low bioavailability of dietary epoxyxanthophylls in humans. Br J Nutr 100: 273-277, 2008.

24. Sherr CJ and Roberts JM: Living with or without cyclins and cyclin-dependent kinases. Genes Dev 18: 2699-2711, 2004.

25. Burstein E and Duckett CS: Dying for NF- $\kappa$ B? Control of cell death by transcriptional regulation of the apoptotic machinery. Curr Opin Cell Biol 15: 732-737, 2003. 